\title{
Amazonas, Amazonas de Glauber Rocha e a música de Villa- Lobos: representações entre passado, presente e futuro
}

Amazonas, Amazonas by Glauber Rocha and Villa-Lobos' music: representations between past, present and future

Amazonas, Amazonas de Glauber Rocha y la música de Villa-Lobos: representaciones entre pasado, presente y futuro

DOI: https://doi.org/10.1590/1809-58442021304

\section{Luiza Beatriz Alvim ${ }^{1}$}

https://orcid.org/0000-0003-4816-6790

${ }_{1}^{1}$ (Universidade Federal do Rio de Janeiro, Escola de Música, Programa de Pós-Graduação em Música. Rio de Janeiro - RJ, Brasil).

\section{Resumo}

Glauber Rocha realizou o documentário de encomenda Amazonas, Amazonas (1966) após Deus e o diabo na terra do sol (1964), lançando mão novamente de músicas de Villa-Lobos: a peça Uirapuru e Estudos para violão, alguns deles já utilizados em Arraial do Cabo (Paulo Cezar Saraceni e Mário Carneiro, 1959). Destacamos as escolhas musicais e como elas, em conjunção com as imagens e outros elementos sonoros, atuam em Amazonas, Amazonas, tendo em vista as representações da região amazônica, entre mitos, sua desconstrução e evocações do subdesenvolvimento e do progresso, em uma estética entre filme institucional e Cinema Novo. Observamos que, na distribuição dos dois conjuntos de peças (Uirapuru e peças para violão) ao longo do filme, para além de uma relação temporal com um passado mítico ou com o presente da região, há uma lógica geográfica. Destacamos também reutilizações da peça Uirapuru em outros filmes.

Palavras-chave: Cinema Novo. Glauber Rocha. Villa-Lobos. Cinema e Música. Representações.

\begin{abstract}
Glauber Rocha made the commissioned documentary Amazonas, Amazonas (1966) after Black God, White Devil (1964), employing once more Villa-Lobos' music: the piece Uirapuru and Guitar studies, some of them already utilized in Arraial do Cabo (Paulo Cezar Saraceni and Mário Carneiro, 1959). We highlight the musical choices and how they, in conjunction with images and other sound elements, act in Amazonas, Amazonas, in view of the representations of the Amazon region, among myths, its deconstruction, and evocations of underdevelopment and progress, in an aesthetic between institutional film and Cinema Novo. We observe that in the distribution of the two sets of pieces
\end{abstract}


(Uirapuru and guitar pieces) throughout the film, besides a temporal relation with a mythical past or with the present of the region, there is a geographical logic. We also highlight reemployments of Uirapuru in other films.

Keywords: Cinema Novo. Glauber Rocha. Villa-Lobos. Cinema and Music. Representations.

\section{Resumen}

Glauber Rocha realizó el documental comisionado Amazonas, Amazonas (1966) después de Dios y el Diablo en la Tierra del Sol (1964), utilizando de nuevo músicas de Villa-Lobos: la obra Uirapuru y Estudios de guitarra, algunos de ellos ya utilizados en Arraial do Cabo (Paulo Cezar Saraceni y Mário Carneiro, 1959). Destacamos las elecciones musicales y cómo éstas, en conjunción con las imágenes y otros elementos sonoros, actúan en Amazonas, Amazonas, ante las representaciones de la región amazónica, entre mitos, su deconstrucción y evocaciones del subdesarrollo y progreso, en una estética entre cine institucional y Cinema Novo. Observamos que, en la distribución de los dos conjuntos de piezas (Uirapuru y los estudios para guitarra) a lo largo de la película, además de una relación temporal con un pasado mítico o con el presente de la región, hay una lógica geográfica. También destacamos la reutilización de la pieza Uirapuru en otras películas.

Palabras-clave: Cinema Novo. Glauber Rocha. Villa-Lobos. Cinema y Música. Representaciones.

O compositor Heitor Villa-Lobos (1887-1959) tem, em sua vasta obra, elementos considerados nacionalistas, como a inclusão de cantos indígenas e evocações dos universos rurais e populares urbanos brasileiros. No cinema, foi o responsável pela música do filme O descobrimento do Brasil (1937), de Humberto Mauro', além de que peças suas foram utilizadas em dois outros filmes do diretor, Argila (1942) e O canto da saudade (1952).

Apesar da associação de Villa-Lobos ao governo de Getúlio Vargas - era o "som do Getúlio”, como afirmou Cacá Diegues em entrevista a Guerrini Júnior (2009, p. 171) - e mesmo à Ditadura Militar (pelo uso de peças dele em filmes de propaganda), a imagem do compositor que os cineastas do Cinema Novo brasileiro quiseram utilizar com a inclusão de suas peças nos filmes foi a de um músico nacionalista, capaz de expressar a identidade brasileira em sua música, tendo sido esta muito empregada nos filmes a partir de então. Para Guerrini Júnior (2009, p. 125), ela se torna uma espécie de “alegoria da pátria”.

Podemos observar a apropriação da música de Villa-Lobos com esse tipo de representação já desde os documentários curtas-metragens de Joaquim Pedro de Andrade de 1959, O mestre de Apipucos e O poeta do Castelo, e, principalmente, em Arraial do Cabo, de Paulo Cezar Saraceni e Mário Carneiro, do mesmo ano, em particular com o uso dos Estudos de violão de Villa-Lobos em associação às imagens de pescadores em seu cotidiano. O violão, instrumento da música urbana reputado à "malandragem”, ganha contornos de “brasilidade” ao ser associado às imagens de pesca tradicional (ALVIM, 2017).

1 Humberto Mauro foi uma referência de “paternidade” para os cineastas do Cinema Novo e é curioso que passa também para eles a referência da música de Villa-Lobos utilizada nos filmes de Mauro. 
Em Deus e o diabo na terra do Sol (Glauber Rocha, 1964), Walter Lima Júnior, assistente de direção de Glauber no filme, conta que teve a ideia de colocar música de VillaLobos ainda durante a etapa de produção e Glauber, tendo ficado impactado com a música, chegou a afirmar depois que o compositor talvez tenha sido quem melhor "colocou todo o Brasil em termos de arte” (apud. GUERRINI JÚNIOR, 2009, p. 127).

Deus e o Diabo na terra do Sol concorreu à Palma de Ouro no Festival de Cannes de 1964, fato que conferiu legitimidade a Glauber Rocha como cineasta. Apesar da nova situação política no Brasil após o Golpe de 1964, ainda por conta do sucesso do longametragem, Glauber Rocha acabou convidado a fazer alguns documentários institucionais. É o caso de Amazonas, Amazonas (1966) e de Maranhão 66, no mesmo ano.

Faremos aqui uma análise do modo de utilização das peças de Villa-Lobos em Amazonas, Amazonas, considerando a relação das peças musicais e representações da região amazônica, entre evocação de mitos, relações identitárias e indicações de subdesenvolvimento ou progresso. Daremos um maior destaque à peça Uirapuru, trazendo também algumas reflexões da área de Musicologia. Além do seu título promover uma associação direta com uma lenda amazônica, tendo sido a música utilizada em outro documentário sobre a região, ela foi reaproveitada depois em um filme posterior de Glauber Rocha, Claro (1975).

\section{O caminho de Glauber até Amazonas, Amazonas}

Em 1965, o governo do Estado do Amazonas estava nas mãos do historiador Arthur Cézar Ferreira Reis, colocado lá por sua amizade com o presidente militar Castelo Branco. Arthur Reis era um grande estudioso da região e defendia a soberania brasileira na Amazônia contra interesses estrangeiros.

Com a intenção de produção de um filme para promover a imagem do Amazonas perante o resto do país, o diretor do Departamento de Turismo e Promoção (DEPRO), Luiz Maximino de Miranda Corrêa, foi quem indicou o nome de Glauber Rocha, exaltando junto ao governador Reis o poder de divulgação e penetração do cinema na sociedade. A indicação de Glauber teve provavelmente a influência do escritor e cineclubista amazonense Márcio Souza, com quem o diretor se correspondia desde 1964 e a quem Glauber teria mencionado o seu desejo de fazer um filme sobre a região, inclusive por concordar com o governador na sua defesa de uma Amazônia brasileira (MENDONÇA, 2018).

O contrato foi firmado em outubro de 1965, porém, Glauber foi preso em novembro de 1965 junto com outros intelectuais que protestavam contra o regime militar em frente ao Hotel Glória, no Rio de Janeiro, durante a abertura da reunião da Organização dos Estados Americanos (OEA), e acaba chegando a Manaus só em 14 de dezembro de 1965 (MENDONÇA, 2018).

Apesar da intenção mencionada a Márcio Souza em carta ao produtor do filme, Luiz Augusto Mendes, Glauber inquietava-se com a responsabilidade e confessava ter chegado lá sem saber nada sobre a região (ROCHA, 1997). É de se perguntar, como o fez Mendonça (2018), os esquemas mentais que Glauber trazia antes de chegar à Amazônia. Mendonça 
(2018) pondera que Amazonas, Amazonas acaba sendo o primeiro filme a cores de Glauber, além de ser um de seus poucos documentários institucionais, o que, de certa forma, entra em contradição com os preceitos do "cinema autoral” defendido pelo Cinema Novo. O quanto o resultado final do filme estaria mais próximo de um ou de outro?

Ainda na carta ao produtor, Glauber esclarece que, embora não pretendesse fazer um tratado socioeconômico e indicasse a sua pouca disposição para fazer um documentário institucional turístico, pretendia mostrar o Amazonas mítico (“selvagem e lendário”), em um contraste entre passado e presente:

Quero lhe esclarecer um detalhe: não houve transformação de documentário turístico em socioeconômico. Houve um quebra-galho porque aqui não há muito o que filmar de turismo. Aqui chegando havia dois problemas: ou fazer uma série de vistas falsificadas para uma propaganda de turismo ou fazer um documentário com o mínimo de intenção que justificasse a onda da qual o mesmo aqui estava cercado com fofocas no governo e etc. O roteirinho que fiz não é complicado [...]: mostrar um pouco do Amazonas selvagem e lendário e um pouco do Amazonas de hoje. Assim haveria um contraste, despertaria algum interesse (ROCHA, 1997, p. 264).

Em outro trecho da carta, Glauber cita uma série de clichês comumente relacionados à Amazônia e a contradição de que fazer um filme "sem índio, sem onça, sem cobra, sem vitória-régia, sem pescaria, sem seringueiro - não é um filme do Amazonas” (ROCHA, 1997, p. 264). O diretor conclui, porém, que considera o "problema dos índios" “indispensável” (ROCHA, 1997, p. 264). É bem verdade que Glauber também esclarece na carta que suas conversas com o governador amazonólogo livrou o documentário de "falhas inevitáveis" (os clichês decorrentes da ignorância do diretor sobre a região?²). Queixa-se também dos inúmeros problemas de produção, como o excesso de chuvas.

Glauber fez, então, um documentário em que utiliza principalmente narração over, mas também inclui uma entrevista em que ele mesmo aparece em quadro, em uma mistura dos modos expositivo, participativo, reflexivo e performático (em relação a estes dois últimos, prefigurando alguns estratagemas de que lançará mão em Di-Glauber, de 1977), cunhados por Nichols (2005). A música é onipresente e constituída por peças de Villa-Lobos: o poema sinfônico/ballet Uirapuru e os Estudos para violão n. 1, 4 e 6.

Antes de fazermos uma análise mais detalhada da música no filme, vamos considerar o próprio Uirapuru dentro da obra de Villa-Lobos e suas relações com as representações amazônicas e de uma suposta "brasilidade” na obra do compositor.

2 É curioso comparar a carta de Glauber ao produtor com a que enviou à filha Paloma no mesmo janeiro de 1966. Nesta última, ele reforça todos os clichês amazonenses para a criança, faz desenhos com uma legenda em que menciona, além de cobra e onça, o "uirapuru” (estaria ele já pensando na música de Villa-Lobos?), assinando “Glauburu”: “Aqui tem muito bicho: arara, papagaio, cobra, peixe-boi, jacaré, onça. O rio aqui é muito grande, quase do tamanho do mar. E tem índio que sempre vem falar com papai. 'Índio quer ver menina Paloma’. Tem índio Mauê, Waupe, Manco, tudo nu, de pena na cabeça, arco e flecha” (ROCHA, 1997, p. 265). 


\section{O caminho de Villa-Lobos até Uirapuru}

Na obra de Villa-Lobos, peças com referências aos índios brasileiros ou suas lendas são principalmente da década de 1920, especialmente com as estadias do compositor em Paris a partir de $1923^{3}$, fase em que ele produz obras consideradas de "vanguarda"4 e marcadas por um "primitivismo", presente em vários compositores admirados na época, como o russo Igor Stravinsky e sua Sagração da Primavera (1913).

"Primitivismo" é definido por Bernstein (2009, p. 25), dentro do contexto da época, como:

um movimento ou inclinação artística e estética surgidos nas primeiras décadas do século XX centrados (... na) rejeição à sociedade burguesa, seus valores considerados fonte de corrupção espiritual - e sua arte, considerada decadente - (... e na) tentativa de reformar a arte (...) com técnicas radicais desenvolvidas a partir da arte de povos não europeus, ditos "primitivos".

As histórias que Villa-Lobos contava aos franceses sobre o seu suposto contato com índios tupinambás antropófagos acabaram caindo como uma luva no imaginário francês, tendo o compositor se convertido à "estética primitivista". Segundo Guérios (2003), o compositor teria "se descoberto" brasileiro em Paris, ou seja, a sua "brasilidade", eivada de "primitivismo", veio a partir do olhar do outro. Musicalmente, o primitivismo é caracterizado por Bernstein (2009, p. 25):

pela animação rítmica dos elementos musicais, ou seja, pela presença abundante de ostinati, notas pedais e fragmentos melódicos que, animados ritmicamente na forma de células repetidas e melodias circulares, tornam-se eles mesmos como que pequenos ostinati.

Entre as peças de Villa-Lobos com tal estética e referências indígenas, estão o Nonetto (1923), os Três Poemas Indígenas (1926) e alguns dos Choros que incluem partes vocais em línguas indígenas, como os Choros n. 3 e o n. $10^{5}$.

Por sua vez, o poema sinfônico Uirapuru, que se refere a uma lenda amazônica, foi datado pelo compositor como sendo de 1917, porém, essa datação é refutada por musicólogos, já que o compositor atribuiu várias datas anteriores às suas peças da época para desvincular

3 A primeira estadia foi de 1923 a 1925; a segunda, de 1927 a 1930.

4 Villa-Lobos foi o único compositor brasileiro a participar da Semana de Arte Moderna de 1922, mas as peças apresentadas tinham estética mais próxima à dos compositores franceses Debussy e Vincent d'Indy.

5 O Nonetto, partes dos Três Poemas Indígenas e o Choros n. 3 estão no filme O descobrimento do Brasil (Humberto Mauro, 1937), com trilha musical de Villa-Lobos, na versão anterior à restauração de 1997 (cuja trilha musical foi totalmente refeita). Segundo Tatyana Jacques (2014), Villa-Lobos aproveitou peças compostas por ele anteriormente, algumas delas em versões diferentes, provavelmente gravadas especialmente para o filme. Essas peças mencionadas não estão nas quatro Suítes do Descobrimento do Brasil, estreadas por Villa-Lobos em diferentes datas e que foram usadas para a trilha musical na restauração do filme de 1997. 
uma possível influência de Stravinsky. Tendo sido a estreia de Uirapuru em 1935, muitos creditam essa peça ao ano de 1934.

Villa-Lobos também tinha o costume de retrabalhar materiais e Salles (2005) indicou a origem do Uirapuru na peça Tédio da Alvorada, composta em 1916 e estreada em 1918. Conforme aponta o teórico, as seções musicais de Uirapuru em que se poderia falar mais de influência de Stravinsky não estão presentes em Tédio da Alvorada, sendo de se supor que tenham sido compostas depois de 1923. Além disso, curiosamente, o musicólogo Manoel Corrêa do Lago $^{6}$ indicou que essa peça tinha uma ambientação na Grécia antiga e não amazônica ou brasileira.

Em sua juventude, entre 1905 e 1915, Villa-Lobos chegou a fazer algumas viagens pelo Brasil, incluindo a região Norte, porém, o seu suposto contato com indígenas na Floresta Amazônica e com suas fontes musicais primárias parecem ser um mito criado pelo próprio compositor. Diferentemente, seu acesso ao material indígena parece ter sido por meio de várias fontes secundárias.

No caso de Uirapuru, Volpe (2009) aventa a hipótese de que o compositor teria conhecido a lenda por meio do livro de 1908 do botânico britânico Richard Spruce (Notes of a Botanist on the Amazon and Andes), que continha, inclusive, uma transcrição musical do canto do pássaro, sendo esta bastante semelhante ao tema do uirapuru no poema sinfônico de Villa-Lobos. Já Felicíssimo (2016) elenca, como possíveis fontes, além do livro de Spruce e da obra $O$ selvagem (1876) de José Vieira Couto de Magalhães (citada pelo pesquisador Eero Tarasti), os livros do médico e romancista carioca Gastão Cruls, Amazônia misteriosa (1925) e Amazônia que eu vi (1930). No primeiro, há a introdução da lenda do uirapuru.

Segundo ela, o canto noturno do uirapuru atraía as índias, a quem tinha sido revelado que o uirapuru era o mais belo cacique existente. Uma noite, ao ouvirem o canto, um grupo delas descobre um índio feio que desafiava o pássaro. As índias o enxotam e procuram pelo pássaro. Uma bela índia o encontra, lança-lhe uma flecha e ele, atingido, transforma-se em um belo índio, sendo, então, disputado por todas as outras. No meio dessa disputa, o índio feio surge e fere mortalmente o índio bonito, que acaba se transformando em um pássaro invisível.

Volpe (2009) considera que, ao levar tal lenda do uirapuru ao seu bailado, Villa-Lobos descartou o sabiá, representante da tradição literária do Romantismo brasileiro, em prol de um pássaro misterioso e mágico, em uma reformulação da convenção romântica do índio identificado com a natureza pela introdução do elemento do "maravilhoso" contido na lenda, com as metamorfoses, primeiro de pássaro para índio e, depois, de índio para pássaro. Para Volpe (2009), a obra se inscreve no “imaginário edênico” oriundo dos escritos coloniais, de viajantes e folcloristas do início do século XX. Curiosamente, é também esse tipo de deslocamento que demonstra a intenção de Glauber Rocha na realização de Amazonas, Amazonas, ao querer mostrar “o Amazonas selvagem e lendário”, e não “onça”, “cobra” ou "vitória-régia".

6 Em palestra no X Simpósio Internacional de Musicologia, no Rio de Janeiro, em 14 de agosto de 2019. 
Por outro lado, a releitura do Indianismo romântico pelo modernismo musical brasileiro indicada por Volpe (2009) encontra paralelos em obras de Stravinsky, mais especificamente, $O$ pássaro de fogo (1910), em cujo conteúdo temático ocorre também uma série de metamorfoses, além de conter elementos musicais próximos a vários presentes em Uirapuru.

Tais aproximações não deixam de reforçar uma estética modernista internacional no início do século XX, em que Villa-Lobos se inseriu e da qual, de certa forma, afastou-se com a série das Bachianas Brasileiras (os seus Estudos para violão estão justamente na transição dessas duas fases). Com efeito, Bernstein (2009) observa que Tarasti considerava os Choros, a cuja maneira de composição se aproxima a do Uirapuru, como representantes de um "Brasileirismo em uma forma de vanguarda internacional”, enquanto as Bachianas estariam "expressando nacionalidade em uma forma muito mais popular, inteiramente tradicional" (TARASTI, 1995, p. 151 apud. BERNSTEIN, 2009, p. 24).

\section{Uirapuru, Estudos para violão de Villa-Lobos, vozes e imagens em Amazonas, Amazonas - entre passado, presente e futuro}

Em Amazonas, Amazonas, há música em praticamente toda a extensão do documentário (Quadro 1): peças musicais são “coladas” umas às outras e há apenas curtas interrupções, geralmente por causa de ruídos de máquinas de alto volume. Nem mesmo a entrevista incluída faz Glauber abdicar da música, que fica como fundo para a fala em primeiro plano sonoro. Essa estética da música ininterrupta junto com voz over foi bastante comum em documentários, especialmente curtas-metragens, dos anos 1950 (por exemplo, em filmes de Alain Resnais, Chris Marker, Jean-Luc Godard, além dos já citados exemplos brasileiros de Joaquim Pedro de Andrade e Paulo Cezar Saraceni e Mário Carneiro) e foi utilizada por Glauber nos seus curta-documentários dos anos 1960 e 1970.

Quadro 1 - Peças de Villa-Lobos em Amazonas, Amazonas

\begin{tabular}{|l|l|l|l|}
\hline & Tempo & Peça musical & No filme \\
\hline 1 & $0^{\prime}-2^{\prime} 01^{\prime \prime}$ & Uirapuru & $\begin{array}{l}\text { Créditos. Planos aéreos da floresta e do rio. Cachoeiras e } \\
\text { interior das florestas. }\end{array}$ \\
\hline 2 & $2^{\prime} 01^{\prime \prime}-2^{\prime} 54^{\prime \prime}$ & Estudo n. 4 & $\begin{array}{l}\text { Continuação. Revoada. Canoa no rio ao fundo. Outra em } \\
\text { plano próximo. Palafita e pessoas trabalhando. Início da } \\
\text { entrevista. }\end{array}$ \\
\hline 3 & $2^{\prime} 54^{\prime \prime}-5^{\prime} 13^{\prime \prime}$ & Uirapuru & $\begin{array}{l}\text { Continuação (entrevista). Trabalhadores com enxadas, serrando } \\
\text { madeira, na lavoura. Plantação. Canoa. Rio. Seringueira. }\end{array}$ \\
\hline 4 & $5^{\prime} 18^{\prime \prime}-6^{\prime} 15^{\prime \prime}$ & Uirapuru & $\begin{array}{l}\text { Plano detalhe da seringueira e extração da borracha. } \\
\text { Seringueiros. }\end{array}$ \\
\hline 5 & $6^{\prime} 37^{\prime \prime}-8^{\prime} 21^{\prime \prime}$ & Uirapuru & $\begin{array}{l}\text { Lustre, interiores e exteriores do Teatro Amazonas. Casas } \\
\text { deterioradas. }\end{array}$ \\
\hline 6 & $8^{\prime} 21-8^{\prime} 45^{\prime \prime}$ & Estudo n. 1 & Vista aérea de Manaus. Placa da cidade. \\
\hline
\end{tabular}




\begin{tabular}{|l|l|l|l|}
\hline & Tempo & Peça musical & No filme \\
\hline 7 & $8^{\prime} 45^{\prime \prime}-10^{\prime} 08^{\prime \prime}$ & Estudo n. 6 & $\begin{array}{l}\text { Ônibus e ruas de Manaus com carroças, carros, pedestres. } \\
\text { Porto. Trabalhadores descarregando caminhão. }\end{array}$ \\
\hline 8 & $11^{\prime} 04^{\prime \prime}-12^{\prime} 49^{\prime \prime}$ & Estudo n. 4 & $\begin{array}{l}\text { Feira. Rio (travelling). Pessoas nas margens ao longe, depois } \\
\text { em planos mais próximos. Canoas. Gado (travelling). }\end{array}$ \\
\hline 9 & $\begin{array}{l}12^{\prime} 50^{\prime \prime} \text { até o } \\
\text { fim }\end{array}$ & Uirapuru & $\begin{array}{l}\text { Continuação. Aldeias ribeirinhas. Homem na rede. Plano } \\
\text { aéreo de rio, refinaria e estrada. Créditos. }\end{array}$ \\
\hline
\end{tabular}

Fonte: autora.

O início do filme com os planos aéreos da floresta em sua imensidão e do Encontro das Águas (do rio Solimões com o rio Negro), além do uso da voz over masculina em uma narração basicamente informativa e condutora das imagens ${ }^{7}$ - bastante comum em documentários clássicos, no "modo expositivo" de Nichols (2005) -, nos sugere uma revisitação crítica de Glauber aos documentários tradicionais de cunho turístico sobre a Amazônia, àqueles que ele disse não ser mais necessário fazer ${ }^{8}$.

Mendonça (2018) atribui esse código visual ao documentário No Rastro do Eldorado (1925), do pioneiro Silvino Santos, que registrou a expedição do geógrafo norte-americano Alexander Hamilton Rice Jr. pela região do rio Branco (na atual Roraima) entre 1924 e 1925. Para Mendonça (2018, p. 98), “por trás desse código está a sugestão de uma paisagem amazônica primeva e homogênea (...), mas que esconde riquezas vegetais e fauna exótica por baixo da floresta tropical”.

Logo a voz over assume uma nova personalidade: sai de seu registro de terceira pessoa e a mesma voz masculina se transforma na do personagem histórico do navegador espanhol Francisco de Orellana (“(...) descobri a 22 de junho de 1542 em missão do reino espanhol. Eu, Francisco de Orellana, enfrentei o desconhecido (...)”9). Nessa mudança de chave, podemos dizer que há também a intenção de Glauber, manifesta em carta aqui mencionada, de mostrar o Amazonas "lendário e selvagem", algo que o Uirapuru (trecho 1 do Quadro 1) de VillaLobos, com todas as suas associações de sentidos anteriormente analisadas e presente desde os créditos iniciais, vinha já sugerindo.

As imagens passam a ser de cachoeiras no interior da floresta, algo que nos remete tanto aos relatos coloniais de conquista quanto a filmes já feitos sobre a Amazônia que apelam para o exotismo. Embora cobras e índios não sejam mostrados na imagem, são evocados pela narração, que se alterna entre o relato pleno do elemento do maravilhoso de Orellana (“(...) dei combate a índios de longos cabelos que lembravam mulheres guerreiras d'outras lendas (...)") e a voz over impessoal em um tom agora crítico (“Inferno verde, paraíso verde, eis a clássica Amazônia onde se pensa no passado, nas cobras gigantescas, (...)”): ela deixa claro

7 Na voz over: “O Negro encontra o Solimões. Duas águas desembocam numa só. Grandes águas, grande rio”.

8 Em carta ao produtor do filme: “sobre o tal 'turismo', o J. Borges fez aqui o Manaus, para o Itamaraty, de dez minutos, que vi, e esgotava o assunto” (ROCHA, 1997, p. 264).

9 Mendonça (2018) observa, porém, que o relato dessa primeira expedição ao longo de toda a extensão do rio Amazonas foi de autoria do frei Gaspar de Carvajal. 
que esse tipo de pensamento sobre a Amazônia (e, por extensão, o tipo de documentário que Glauber parece estar fazendo no início) é coisa do passado. Por outro lado, como observa Mendonça (2018), essa guinada de posição do documentário está em sintonia com o esforço empreendido pela intelectualidade amazonense, incluindo o governador Arthur Reis, de chamar a atenção para os problemas socioeconômicos locais de maneira realista e não fantasiosa, além de revelar a potencialidade econômica da região.

A mudança da música para o Estudo n. 4 de Villa-Lobos (trecho 2 do Quadro 1) no meio do plano indica que, possivelmente, algo também mudará na dinâmica do filme. Efetivamente, alguns segundos depois, começamos a ver, além da natureza, o elemento humano: primeiramente, vemos uma canoa com duas pessoas na profundidade do plano do rio; depois, outra canoa com pessoas é vista em planos mais próximos e, a seguir, vemos pessoas trabalhando junto a uma palafita: o trabalho humano passa definitivamente ao centro do documentário, assim como não é mais a Amazônia do passado que lhe interessa, mas a do presente que constrói um futuro, destacada também pela voz over:

O Amazonas que conhecemos é outro. O Amazonas de hoje, maior Estado do Brasil, onde o homem já fixou suas raízes e luta para desenvolver sua civilização, onde o homem, transformando árvores em casas, busca uma cultura a partir das condições especiais do meio.

Mendonça (2018) chama a atenção que essa ênfase no humano como elemento produtivo e não simplesmente como parte da paisagem natural, por um lado, já era presente em representações dos documentários clássicos produzidos na região no início do século XX, por outro, fazia parte de um projeto político de integração da região ao país durante a Ditadura Militar em oposição aos interesses estrangeiros e ao subdesenvolvimento. Além disso, consideramos que, nesse momento, embora o Estudo de Villa-Lobos seja ouvido ainda em uma região de floresta, o elemento humano indica a cidade próxima, apontando para um aspecto geográfico de diferenciação na utilização das músicas no documentário (Uirapuru e Estudos), para além do temporal (passado e presente).

Pois, se levarmos em conta as associações intertextuais decorrentes do uso da música no documentário Arraial do Cabo (1959), a própria presença das peças para violão de VillaLobos em Amazonas, Amazonas nos evoca o elemento humano e, em certa medida, o urbano. No filme de Saraceni e Mário Carneiro, como analisamos em artigo anterior (ALVIM, 2017), peças para violão (Estudos n. 1, 5, 8 e 11; Prelúdios n. 1 e 4) são colocadas em imagens do cotidiano dos pescadores, em uma associação de sentido de "brasilidade”. Houve, com efeito, uma ênfase em uma primeira fase do Cinema Novo, com influência do neorrealismo italiano, no rural e nos trabalhadores de pequenas cidades como síntese do verdadeiro Brasil que não era mostrado nas telas. É curioso, no entanto, que, embora Villa-Lobos também tivesse se interessado por esse Brasil rural, sua música para violão vem do seu contato com os chorões, com o “popular urbano”. 
Ainda ouvimos o Estudo n. 4, quando começa a entrevista de Glauber com um trabalhador da região. A música logo troca para o Uirapuru (trecho 3 do Quadro 1). Não conseguimos, portanto, fazer uma associação do Uirapuru unicamente às partes do filme relacionadas ao "Amazonas lendário" e dos Estudos de violão ao "Amazonas do presente” (lembrando o "contraste” intencional de Glauber, como dito em sua entrevista anteriormente citada), já que o filme, a partir daí, é quase todo focado nesse segundo, com exceção dos planos do Teatro Amazonas (ao som do Uirapuru) e sua associação com as glórias do passado. Porém, é possível, sim, relacionar o Uirapuru a um ambiente mais da floresta (suas populações ribeirinhas, os trabalhadores rurais, os seringueiros e o resultado da extração da borracha: o teatro) e os Estudos ao urbano de Manaus como grande cidade, numa associação, como anteriormente mencionado, mais geográfica que temporal, sendo os trechos com o Estudo n. 4 (trechos 2 e 8) mistos (com o urbano e o rural), como uma ponte para o Uirapuru, que também fecha o filme ${ }^{10}$.

Assim, a entrevista, ao som do Uirapuru (trecho 3), dá-se em uma paisagem de uma clareira próxima a troncos de árvores e o entrevistado menciona o problema da posse de terra, ao passo em que, com o som da sua fala e da música, vemos imagens de outros trabalhadores. Glauber interrompe bruscamente, de forma brechtiana, com um "Corta!”"11, enquanto vemos um homem trabalhando a terra, possivelmente um empregado e não o seu dono. Mendonça (2018) se questiona se o corte da entrevista não seria uma crítica velada de Glauber à questão da terra que lhe era muito cara (como se pode perceber em Deus e o diabo na terra do sol) e à possibilidade de censura por expô-la.

No final do trecho 3, já sem o som da entrevista, ouvimos apenas uma parte do Uirapuru cuja estética lembra bastante a de Stravinsky, com seus ostinatos, enquanto acompanhamos o travelling ao longo do rio, criando uma sensação de urgência, que vai terminar no tronco de uma árvore (que veremos depois ser uma seringueira), no corte brusco da música, com o recomeçar da voz over em uma nova investida de narrador-personagem: agora são os seringueiros que dizem "Viemos de longe do sertão do Ceará, tangidos pela seca, buscando na selva riqueza para nossa fome. A esperança estava nas árvores que os índios Cambebas ${ }^{12}$ haviam descoberto. Nas grandes árvores perdidas que sangravam a estranha mistura”.

No meio dessa narração começa outro trecho (4) do Uirapuru, com o tema do pássaro. Os processos de extração da borracha são mostrados ao som da música, interrompida pelo

10 Na observação do aluno Marcos de Oliveira (em disciplina da pós-graduação em Música da UFRJ, no primeiro semestre de 2019), quase todas as imagens do filme mostram o rio, em uma relação tão inequívoca quanto a duplicação do nome "Amazonas" no título (referência ao Estado e ao rio que o nomeia). Além da relação intrínseca de populações da região Norte com os rios (meio de subsistência, transporte etc), o próprio Glauber Rocha mostra ter uma fascinação pelo mar, presente no fechamento de seu Deus e o diabo na terra do sol (1964), na abertura de Terra em transe (1967), elemento fundamental em Barravento (1962) e mesmo no experimental O pátio (1959), nas bordas do enquadramento. Lembremos também a carta já evocada do diretor à filha, em que ele frisa que o rio Amazonas é muito grande, "quase do tamanho do mar".

11 Tal exposição do fazer fílmico, com reflexividade e modo performático (NICHOLS, 2005), estará presente igualmente no documentário Di-Glauber (1977).

12 São pouquíssimas as menções diretas aos indígenas, só presentes nas imagens enquanto trabalhadores aculturados nas cidades ou como elemento a-histórico (MENDONÇA, 2018). Glauber, definitivamente, não resolveu “o problema dos índios”. 
ruído das máquinas do lugar identificado por Mendonça (2018) como a Companhia Nacional de Borracha, inserida na realidade presente de Manaus dos anos 1960.

O corte para o espaço do Teatro Amazonas faz voltar a música (trecho 5). Embora as imagens tenham sido feitas por Glauber no presente, a suntuosidade do teatro evoca a glória do passado, decorrente do Ciclo da Borracha. O narrador volta a adquirir o caráter onisciente de terceira pessoa e a música é, mais uma vez, o Uirapuru, que bem poderia ter feito parte daquele cenário como bailado ${ }^{13}$. Ouvimos o tema do pássaro mais uma vez, um vislumbre de tempos míticos que, agora, não se referem apenas ao elemento lendário, mas também ao aspecto da bonança decorrente dos tempos já longínquos (míticos também, nesse sentido) da exploração da borracha, tal como dito na voz over: "A ambição que gerou a conquista. [...] Era o Eldorado”. A seguir, dissonâncias na música, junto com a narração da crise provocada pela concorrência com a borracha produzida nas colônias inglesas da Ásia, ficam sobre imagens de palacetes de arquitetura Belle Époque em estado de deterioração.

O corte brusco e mudança para um plano aéreo de Manaus coincidem com a troca da música para o Estudo n. 1 de Villa-Lobos (trecho 6). Como vimos, este trecho e os dois seguintes (7 e 8) com outros Estudos para violão estão nos espaços urbanos, reforçando a mudança geográfica da narrativa do filme da floresta (incluindo, a borracha e seus efeitos no Teatro Amazonas) para a capital amazonense. Para Mendonça (2018, p. 113), em toda essa parte do filme, "a intenção não é mais realçar apenas os elementos arquitetônicos (essencialmente ligados ao passado) que reforcem o discurso da cidade em crise, mas atualizar o espectador em relação ao estado atual da capital amazonense, que passa a sintetizar a situação de todo o Estado.” É a Manaus da integração, que “espera que o Amazonas seja incorporado ao Brasil” (na narração over).

A transição para o trecho 7, com a mudança para o Estudo n. 6, é feita de forma quase imperceptível junto com o corte para planos que mostram uma série de ônibus, movimentando-se todos para a direita da tela. Em contraste, planos em travelling para a esquerda mostram carroças, como em uma representação do que se precisaria vencer para atingir as metas do projeto desenvolvimentista de Arthur Reis. Já a música, em um e no outro movimento, é sempre em progressão contínua de acordes. O movimento se mantém na forma de travellings pelas ruas da capital e a progressão dos acordes continua, como em um reforço daquilo que se quer mostrar nessa parte do filme: a cidade essencialmente moderna, embora com resquícios de elementos arcaicos. Os acordes da música ficam em andamento ainda mais rápido e continuamos a ver movimentos sobre trilhos, agora no porto de Manaus, mostrando o que seria considerado como meta para o desenvolvimento da região.

A música é interrompida pelo ruído de um motor. Passamos a ver uma feira na região do porto, com seus carregadores de bananas, a dura realidade do presente que "faz pensar no mais remoto passado”, na Amazônia como "a região mais subdesenvolvida do país”, como diz a voz over. Ainda nas últimas imagens da feira, começamos a ouvir o Estudo n. 4 (trecho

13 Não sabemos se houve efetivamente apresentações do bailado ali. 
8). Porém, logo se emenda com imagens do rio e de populações ribeirinhas. A voz over diz: "Retornamos a viagem. Foi difícil vencer índios, fazer colonos portugueses se cruzarem com estes índios vencidos, forjar a nova raça, lutar contra o impaludismo, a verminose, conquistar os barrancos devastados pela força do rio instável”. É como uma volta ao início do filme, ao trecho 2, também com o Estudo n. 4, que começava justamente com as imagens do rio, embora ainda evocando o elemento urbano.

O Estudo n. 4 emenda com o Uirapuru (trecho 9) no meio de um travelling que mostra o gado à beira do rio. Para Mendonça (2018, p. 127), essa parte final do documentário tem um tom de "exaltação de um Amazonas que tenta se reerguer acima das adversidades", apontando para um futuro e mostrando um “Amazonas real, sem fantasmas” (na narração over). Mais uma vez, o canto do uirapuru, agora sobre a imagem de um homem local com traços físicos indígenas, deitado em uma rede (uma evocação longínqua do índio da lenda?). No final, um trecho da música à la Stravinsky com ostinato remete à necessidade modernista brasileira de “acertar o compasso da História”, necessidade esta “desenvolvimentista” que o filme afirma também, tendo como imagens finais o plano aéreo da Refinaria Isaac Sabbá e o de uma estrada cortando a floresta (identificada por Mendonça como possivelmente a Manaus-Itacoatiara). Aqui, o Uirapuru está na floresta, porém, em uma floresta invadida pelo urbano.

\section{O Uirapuru para além de Amazonas, Amazonas: outras apropriações}

Bem antes de Glauber se apropriar da peça de Villa-Lobos como trilha musical, uma obra audiovisual foi realizada tendo como base a própria peça musical em si e a lenda em 1950, quando Villa-Lobos ainda era vivo. Foi o filme homônimo Uirapuru, realizado pelo israelense Sam Zebba, com apoio da Universidade da Califórnia em Los Angeles (UCLA), onde Zebba estudava Cinema, e do cônsul brasileiro em Los Angeles na época, Vinícius de Moraes. Segundo o que relata Zebba (2010), Villa-Lobos parece não ter tido participação no filme além da cessão dos direitos para o uso da música.

Zebba (2010) conta que a descoberta de um LP com a música de Villa-Lobos foi o que lhe deu a ideia do filme. Ele seguiu o roteiro da lenda, filmando na Amazônia brasileira com os índios Urubú-Káapor, no Maranhão. O filme retira as referências noturnas da lenda, passando-se sempre em ambientes diurnos. Para Santos (2014), isso se deve provavelmente às dificuldades de produção de filmagens à noite.

Não sabemos se Glauber teve acesso ou sabia da existência do filme de Zebba. O fato é que a peça Uirapuru parece ter ficado bem marcada para ele, já que o diretor a emprega novamente em um filme de 10 anos depois, Claro (1975), e em contexto bem diferente.

Claro foi filmado em Roma, na época do exílio de Glauber. Trechos do Uirapuru são ouvidos principalmente no primeiro terço do filme, em que vemos a atriz francesa Juliet Berto, namorada de Glauber na época, fazendo uma performance nas ruas da cidade, sob orientação do diretor, que aparece em cena. Ela parece dançar, com um poncho aberto, assemelhando-se às asas de um pássaro, o que talvez tenha induzido Glauber a incluir nesses 
trechos esta peça específica de Villa-Lobos (há outras peças do compositor no filme, como as duas partes das Bachianas $n$. 5, tendo sido a sua Cantilena já utilizada em Deus e o diabo na terra do sol).

\section{Conclusão}

Glauber Rocha vai ao Amazonas no final de 1965, convidado pelo Governo do Estado, para realizar um documentário institucional, não querendo repetir clichês de filmes turísticos - o que também não era a intenção do governo, mais interessado em que fosse enfatizado o caráter de integração da região ao país - e partindo de um esquema em que pretendia fazer um contraste entre o “Amazonas lendário” e o “Amazonas do presente”.

Esse aspecto está em Amazonas, Amazonas, um híbrido entre documentário tradicional expositivo, participativo, reflexivo e performático ${ }^{14}$, contendo também uma polifonia no sentido bakhtiniano na voz over que o guia, dividida entre a voz do saber em terceira pessoa e a voz subjetiva dos primeiros exploradores da região e a dos seringueiros, em uma confluência de diversos tempos.

Porém, ao analisarmos as músicas de Villa-Lobos empregadas ao longo do filme, observamos que a sua distribuição não funciona exatamente e unicamente dessa forma, embora uma delas, o Uirapuru, seja diretamente ligada a uma lenda amazônica e poderia se prestar a esse papel, além de que os Estudos de violão, pelo caráter simbólico do instrumento no início do século XX (relacionado aos chorões e ao ambiente urbano) poderiam se prestar ao “Amazonas do presente".

Percebemos, aí, um contraste um pouco mais sutil, mais ligado ao elemento geográfico que ao temporal: o Uirapuru se relaciona mais à floresta, seja às suas associações com o passado ou o presente, com suas populações ribeirinhas, seringueiros e o belo teatro, símbolo do Ciclo da Borracha, ao passo em que os três Estudos de violão (n. 1, 4 e 6) se associam mais ao urbano de Manaus como grande cidade, com todas as suas contradições, seja o progresso tão almejado pelos financiadores do filme, seja a coexistência dele com o antigo (como na sequência, em que após o trânsito de ônibus, vemos a carroça) e a pobreza.

Evocamos também, no artigo, várias reutilizações dessas peças musicais em outros filmes.

\section{Referências}

ALVIM, L. Música e som em três documentários brasileiros curta-metragem de 1959: nacionalismos, tradição, modernismos e identidade brasileira. Doc On-Line, n. 22, p. 163-184, set. 2017.

BERNSTEIN, G. Os Choros e as Bachianas como princípios composicionais. Brasiliana (Revista da Academia Brasileira de Música), n. 29, p. 23-30, ago. 2009.

14 Segundo os modos de Nichols (2005). 
FELICÍSSIMO, R. Uirapuru: a lenda do pássaro encantado, de Heitor Villa-Lobos. In: II SIMPÓSIO NACIONAL VILLA-LOBOS. Rio de Janeiro, nov. 2016. Anais....

GUÉRIOS, P. R. Heitor Villa-Lobos: o caminho sinuoso da predestinação. Rio de Janeiro: Editora FGV, 2003.

GUERRINI JÚNIOR, I. A música no cinema brasileiro: os inovadores anos sessenta. São Paulo: Terceira Margem, 2009.

JACQUES, T. O descobrimento do Brasil (1937): Villa-Lobos e Humberto Mauro nas dobras do tempo. 428 f. Tese (Doutorado em Antropologia Social) - Universidade Federal de Santa Catarina, Florianópolis, 2014.

MENDONÇA, R. N. Amazônia de Glauber Rocha: uma análise do documentário Amazonas, Amazonas. 166 f. Dissertação (Mestrado em Sociedade e Cultura na Amazônia) - Universidade Federal do Amazonas, Manaus, 2018.

NICHOLS, B. Introdução ao Documentário. Campinas: Papirus, 2005.

ROCHA, G. Cartas ao mundo. Org.: Ivana Bentes. São Paulo: Companhia das Letras, 1997.

SALLES, P. T. Tédio de Alvorada e Uirapuru: um estudo comparativo de duas partituras de Heitor VillaLobos. Brasiliana (Revista da Academia Brasileira de Música), n. 20, p. 2-9, maio 2005.

SANTOS, D. Z. Uirapuru de Villa-Lobos e Sam Zebba: uma análise comparativa entre música e cena. In: XXIV CONGRESSO DA ASSOCIAÇÃO NACIONAL DE PESQUISA E PÓS-GRADUAÇÃO EM MÚSICA, São Paulo, 2014. Anais....

VOLPE, M. A. Villa-Lobos e o imaginário edênico de Uirapuru. Brasiliana (Revista da Academia Brasileira de Música), n. 29, p. 31-36, ago. 2009.

ZEBBA, S. Making "Uirapuru”: a musical quest in the Brazilian Rain Forest. Bol. Mus. Para. Emílio Goeldi. Cienc. Hum., Belém, v. 5, n. 1, p. 173-184, jan./abr. 2010.

\section{Luiza Beatriz Alvim}

Pós-doutoranda em Música na Universidade Federal do Rio de Janeiro. Doutora em Comunicação pela Universidade Federal do Rio de Janeiro e em Música pela Universidade Federal do Estado do Rio de Janeiro. Foi professora-substituta da Escola de Comunicação da Universidade Federal do Rio de Janeiro e do Departamento de Cinema e Vídeo da Universidade Federal Fluminense. Autora do livro “A música no cinema de Robert Bresson”. Coordenadora do GP Cinema da Intercom. E-mail: luizabeatriz@yahoo.com.

Recebido em: 17.01 .2020

Aprovado em: 20.12.2020

Este artigo é publicado em acesso aberto (Open Access) sob a licença Creative Commons Attribution Non-Commercial (CC-BY-NC), que permite uso, distribuição e reprodução em qualquer meio, sem restrições, desde que sem fins comerciais e que o trabalho original seja corretamente citado.

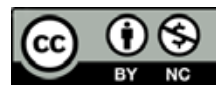

